REVIEW

\title{
Point of controversy: perioperative care of patients undergoing pheochromocytoma removal-time for a reappraisal?
}

\author{
Claude Lentschener ${ }^{1}$, Sebastien Gaujoux ${ }^{2}$, Antoine Tesniere ${ }^{1}$ and Bertrand Dousset ${ }^{2}$ \\ Departments of ${ }^{1}$ Anesthesia and Critical Care and ${ }^{2}$ Digestive and Endocrine Surgery, Faculté de Médecine, Assistance Publique - Hôpitaux de Paris, Hôpital \\ Cochin, EA 3623, Université Paris-Descartes, 27 rue du Faubourg Saint Jacques, 75679 Paris Cedex 14, France \\ (Correspondence should be addressed to C Lentschener; Email: claude.lentschener@cch.aphp.fr)
}

\begin{abstract}
Adrenalectomy for pheochromocytoma is reported with a mortality close to zero in recent studies. The dogma of preoperative fluid and hypotensive drug administrations is widely applied in patients scheduled for pheochromocytoma removal and is assumed to have a beneficial effect on operative outcomes. This paradigm is only based on historical studies of non-standardized practices and criteria for efficacy, with no control group. Pre- and intraoperative hypovolemia have never been demonstrated in patients scheduled for pheochromocytoma removal. Recent improvements in outcome of patients undergoing adrenalectomy for pheochromocytoma could also be the result of improvement in surgical techniques and refinement in anesthetic practices. Whether better knowledge of the disease, efficiency of available intravenous short-acting vasoactive drugs, and careful intraoperative handling of the tumor make it possible to omit preoperative preparation in most patients scheduled for pheochromocytoma removal is presently questionable. We reviewed available literature in this respect.

European Journal of Endocrinology 165 365-373
\end{abstract}

\section{Clinical and pathophysiological considerations}

Pheochromocytoma symptoms result from the uncontrolled release of catecholamines: norepinephrine, epinephrine, and rarely dopamine (1-5). Compared with norepinephrine release, epinephrine has a predominant effect on $\beta 2$-adrenoreceptors of the vessel muscles resulting in vasodilation and postural hypotension $(1,2,5)$. Norepinephrine release acts predominantly on $\beta 1$ - and $\alpha 1$-adrenoreceptors resulting in vasoconstriction and hypertension $(1,2,5)$. The release of both catecholamine types stimulates $\beta 1$-adrenoreceptors resulting in an increased heart rate $(1,2,5)$. Elevated blood glucose level is primarily due to stimulation of lipolysis and inhibition of glucose uptake in muscle cells and also to glycogenolysis and gluconeogenesis in the liver by epinephrine $(1,6,7)$. Depending on whether catecholamines are released continuously or in shorter bursts, patients will mainly have sustained high blood pressure or a classical presentation consisting of paroxysmal episodes of hypertension associated with headache, sweating, chest pain, tachyarrhythmia, diaphoresis, and flushing $(1,2,5)$. Patients with exclusively dopamine-secreting tumors present with non-specific signs such as unexplained cough, abdominal pain, flank mass, or inflammatory features and are reported to be normotensive (8). Severe high blood pressure associated with pheochromocytoma may cause death from stroke, left-ventricular failure, myocardial infarction, or multiorgan failure $(1,5,9)$. Pheochromocytoma accounts for $0.05-0.1 \%$ of patients with sustained hypertension $(1,5)$. This hypertension is frequently poorly controlled with standard medications $(1,5)$. Fifteen to twenty percent of pheochromocytomas do not secrete significant quantities of catecholamines but, however, run the same risk of life-threatening complications $(1,3)$. With the widespread use of cross-sectional imaging, $29.4-57 \%$ of pheochromocytomas present without clinical symptoms and are found incidentally (3). The only curative treatment for pheochromocytoma is complete surgical resection. The laboratory diagnosis of these tumors is based on the identification of excessive secretion of catecholamines and/or of their derivatives $(2,5)$. Most tumors are benign $(1,5,10-12)$. Laparoscopic adrenalectomy has become the standard treatment for most pheochromocytomas even larger than $7 \mathrm{~cm}$ with, in recent studies, a mortality close to zero when performed by experienced teams (10-12).

\section{Historical background}

In early studies, life-threatening intraoperative catecholamine release has been quickly identified as 
the cause of increased blood pressure, various cardiac arrhythmias including ventricular tachycardia and fibrillation, left ventricular failures, myocardial ischemias, and strokes following induction of anesthesia or tumor manipulation $(13,14)$. Prolonged postoperative hypotension followed the abrupt withdrawal of circulating catecholamines associated with tumor removal and accounted for most operative deaths (15). Pheochromocytoma removals were associated with a mortality rate of $20-45 \%$ in first reports $(13,14)$. Prolonged high preoperative levels of circulating vasopressors released from pheochromocytomas were assumed to cause a vasoconstriction, leading to arterial hypertension and a chronic decrease in blood volume (13-15). The subsequent sudden intraoperative withdrawal of vasopressors following pheochromocytoma resection was believed to cause abrupt relaxation of the vascular bed, in turn resulting in hypotension and shock unless the reduced blood volume was restored (13-15). This led to the assumption that optimal preoperative care had to include preoperative vasodilation of the previously constricted vascular compartment by a vasodilating drug along with restoring blood volume by major fluid infusion $(5,13-30)$.

Mortality has no longer been reported in most recent studies of patients undergoing pheochromocytoma removal $(11,12,18,22,31)$. This improved prognosis is currently attributed to the widespread preoperative administration of vasodilating drugs and large fluid volumes, even in patients with normal or borderline elevation of catecholamine levels $(5,13-30)$. Nevertheless, none of these practices are evidence based, and to our opinion, a critical review of the available literature does not support this dogma.

\section{Fluid administration}

Various amounts and types of fluids have been administered to patients scheduled for pheochromocytoma removal. In 1954, Thompson \& Arrowod (14) reported better intra- and post-operative hemodynamic control following the empirical administration of whole blood transfusions to a level greater than the estimated blood loss. However, at that time, estimated blood loss ranged between 500 and $26000 \mathrm{ml}$ and patients received long-acting hypotensive drugs preand intraoperatively $(13,14)$. Hypovolemia, due to delayed compensation for intraoperative blood loss intensified by long-acting $\alpha$-blockade, could be the main reason for hemodynamic improvement with blood transfusion. Ulchaker et al. (30) reported 127 patients undergoing pheochromocytoma removal with highvolume fluid administration and no postoperative death. Patients routinely received between 1000 and $16400 \mathrm{ml}$ crystalloids and up to $5300 \mathrm{ml}$ colloids, intraoperatively (30). Between 1665 and $11665 \mathrm{ml}$ fluids was infused on postoperative day 1 (30). In addition, up to $2800 \mathrm{ml}$ blood was infused (30). On the contrary, Gosse et al. (22) routinely infused only $2000 \mathrm{ml}$ saline from 10 to 2 days prior to surgery, and Lentschener et al. (31) and Lebuffe et al. (18) administered fluids only as required when intraoperative arterial pressure decreased following adrenalectomy. Lentschener et al. (31) did not report any death, and Lebuffe et al. (18) reported only three deaths neither related to pheochromocytoma nor related to arterial hypertension. In view of these results, it seems very unlikely that major fluid administration is responsible for the improvement of outcome in pheochromocytoma surgery $(18,30-34)$.

\section{Are patients with pheochromocytoma hypovolemic?}

Early fundamental data do not support the concept of clinically significant hypovolemia associated with pheochromocytoma (35-37). Plasma volume was determined in 15 patients with pheochromocytoma before any therapy and in ten of these patients after hypotensive drug administration or adrenalectomy, by using human albumin labeled with ${ }^{125} \mathrm{I}$ (35). All but two patients had normal predicted plasma volume at first assessment (35). Following $\alpha$-methyl-paratyrosine or phenoxybenzamine therapy, the mean plasma volume increased by $11 \%$, and following surgery, the mean plasma volume increased by $6 \%$, when compared with preoperative measurements (35). Finnerty et al. (36) showed a reversible $15 \%$ decrease in plasma volume following a $15 \mathrm{~min}$ infusion of levarterenol, an $\alpha$-blocking drug, in ten human volunteers. Such changes in blood volume are of little clinical relevance (37). Furthermore and importantly, as early as 1977 , when comparing two personal historical studies of patients undergoing adrenalectomy for pheochromocytoma, Desmont \& Marty (16) reported that administering fluid only intraoperatively, whenever necessary, was as efficient as preoperative fluid infusion in regard to hemodynamic control. More recently, analysis of the arterial pressure waveform during mechanical ventilation was used to measure the negative component $(\Delta$-down) of the respiratory systolic pressure variation in 13 patients undergoing pheochromocytoma surgery (38). During tumor removal, the stability of $\Delta$-down and the lack of correlation between systolic arterial pressure variation and $\Delta$-down suggest that reduced preload associated with hypovolemia is not a major mechanism of hypotension following pheochromocytoma removal (38). Furthermore, $\Delta$-down values recorded prior to adrenal vein ligation in patients in whom arterial hypotension occurred after tumor removal overlapped those recorded in patients who remained normotensive. This suggests that the predominant mechanism of severe hypotension following tumor resection is likely to be a decrease in arterial tone and that severe hypotension 
may occur in normovolemic patients (38). Further studies are warranted to assess whether hypotension associated with pheochromocytoma removal is not related to a transient drop in the sympathetic tone as is the case with hypotension associated with the onset of central neural blockade using local anesthetics (39). This situation has widely been documented in the anesthetic literature (39). Following central neural blockade using local anesthetics, after a long period of intense fluid administration, current accepted recommendations are presently focusing on vasopressor administration (39).

\section{Preoperative hypotensive drugs}

Various hypotensive drugs have been preoperatively administered to patients scheduled for pheochromocytoma removal $(13,16,18-20,21,24,26,29,30,32$, 40-44).

- Oral phentolamine is no longer used in the preoperative hypotensive treatment of patients scheduled for pheochromocytoma removal (20).

- Phenoxybenzamine, irreversibly bound to $\alpha 1$ - and a2-adrenoreceptors, is still administered for preoperative management of patients undergoing adrenalectomy for pheochromocytoma $(13,21,24,40)$. Oral phenoxybenzamine has a pharmacological halflife of $24 \mathrm{~h}(13,21,24,40)$. Phenoxybenzamine produces significant postural hypotension and reflex tachycardia due to the blockade of $\alpha 2$-receptors, along with sedation $(13,21,24,40)$. It necessitates careful dose titration $(13,21,24,40)$. It has been suggested that its long duration of action has contributed to the hypotension following pheochromocytoma removal $(13,21,24,40)$.

- Selective $\alpha 1$-antagonists such as terazosin and prazosin have a relatively short duration of action as a result of their competitive inhibition of $\alpha 1$ adrenoreceptors and therefore could minimally potentiate the risk period for the hypotension, which follows a decrease in catecholamine levels (19, 29, 30, 41). This contrasts with doxazosin, which has a half-life of $16-30 \mathrm{~h}$ and has also been suggested to worsen hypotension associated with adrenalectomy $(19,29,30,41)$. They have a minimal effect on cardiac function due to their $\alpha 1$ receptor selectivity $(19,29,30,41)$. Side effects of all a1-adrenergic blockers include postural hypotension, syncope, and nasal congestion and necessitate careful titration $(19,29,30,41)$.

- Calcium channel blockers cause smooth muscle relaxation in peripheral and coronary arteries by inhibiting norepinephrine-stimulated calcium influx into vascular smooth muscle (42). Calcium channel blockers have been used alone as primary treatment, or associated with selective $\alpha 1$-receptor blockers, to successfully control blood pressure in patients with pheochromocytoma (18). Calcium channel blockers are often reported to produce minimal hypotension and to be safe to use in normotensive patients with occasional episodes of paroxysmal hypertension $(18,42)$. It was suggested that catecholamineinduced spasms of coronary arteries were prevented with preoperative calcium channel blockers (42).

- $\beta$-Receptor blockers are preoperatively administered to reduce and/or to prevent pre- and intraoperative tachycardia and cardiac arrhythmias $(16,19,32)$. Propranolol, atenolol, and metoprolol have been routinely used for this purpose $(16,19,32)$. In the absence of adequate $\alpha 1$-blockade, $\beta$-blockade may exacerbate epinephrine-induced constriction by blocking its vasodilator component and precipitate left ventricular insufficiency (43). Cardioselective $\beta 1$-adrenoreceptors should be favored (44).

- Labetalol is a $\beta$-blocker with $\alpha$-blocking properties (26). Labetalol, with $\alpha$ - and $\beta$-antagonistic activities in a ratio of about $1: 7$, may result in paradoxical hypertension (26).

- Structural analogs of tyrosine such as $\alpha$-methyltyrosine are competitive inhibitors of tyrosine $\beta$-hydroxylase, a main step in catecholamine synthesis $(16,21,45,46)$. This drug significantly depletes catecholamine. It was efficiently used to control preoperative high blood pressure in patients with pheochromocytoma $(16,21)$. At the present time, it is used only in few institutions in association with vasodilator drugs to control high blood pressure in patients with extensive metastatic disease for which complete resection is not possible (45).

\section{Are preoperative hypotensive drugs necessary?}

Preoperative blood pressure control is believed to be one of the main causes of the decrease in mortality associated with pheochromocytoma removal. The study by Goldstein et al. (21), often cited as reference, illustrates the low level of evidence of this contention. From 1950 to 1998, authors observed 108 pheochromocytomas (21). Preoperative $\alpha$-blockade consisting of phenoxybenzamine was first used in that institution in 1967 (21). Thereafter, since 1997, patients have received a heterogeneous drug regimen between 1 day and several weeks prior to surgery (21). Since 1973, $\alpha$-methyl-tyrosine has also been used as a blocking agent in 43 patients in combination with phenoxybenzamine (21). Based on this 48-year followup, authors concluded that hypotensive drugs were responsible for a decrease in complications from 69 to $3 \%$ (21). However, this period saw a huge improvement of both surgical approach and anesthetic management. Before 1978, all pheochromocytomas were resected using a thoracoabdominal approach (21). After 1979, 
midline abdominal incision became the preferred approach (21). Beginning in 1998, laparoscopy has been selectively used in three patients (21). All recent studies included various preoperative hypotensive drugs and preoperative fluid regimens and reported a mortality close to zero in patients undergoing pheochromocytoma removal $(5,16-19,22,26,27,29,31$, $32,34,41,47)$. However, available reports do not comply with the rules of scientific investigation. To our knowledge, studies of preoperative hypotensive drugs did not include a non-treated or a placebo control group $(13-34,41,45-49)$. In most reports, despite treatment, preoperative blood pressure control was not achieved. Thus, preoperative systolic blood pressure ranged from 95 to $183 \mathrm{mmHg}$ after $\alpha$-blockade in Bruynzeel et al. (48) report of 73 patients scheduled for pheochromocytoma removal. Two studies compared patients undergoing pheochromocytoma removal with normal and increased preoperative arterial pressures and failed to show any differences in the outcome of patients $(25,31)$. In a study by Lentschener et al. (31) on 96 patients undergoing pheochromocytoma removal with no mortality, 35 patients had high preoperative arterial pressure. In this study, a high preoperative arterial pressure was not indicative of intra- and post-operative hemodynamic instability (31). Plouin et al. (25) reported that high preoperative arterial pressure was independently correlated with intra- and post-operative complications. However, the emphasis in that article was on non-hypertensionrelated complications such as allergy, pneumothorax, postoperative bleeding, or pancreatitis (25). Others compared patients receiving preoperative hypotensive drugs to patients who did not receive any preoperative drugs. In Ulchaker et al. (30) report, 30\% of patients received no medication in the $24 \mathrm{~h}$ preceding surgery. Intraoperative mean blood pressure levels were similar when comparing patients who were or were not treated preoperatively with antihypertensive medications (30). Boutros et al. (34) compared 31 patients receiving phenoxybenzamine or prazosin with 29 patients who did not receive any hypotensive drugs. Crystalloids were infused during the $48 \mathrm{~h}$ prior to surgery in all patients (34). Preoperative blood pressures were increased in most investigated patients (34). No difference in perioperative mortality or morbidity was found, although intraoperative blood pressure rise was a little higher in the untreated group (34). Desmont \& Marty (16) retrospectively evaluating their practices found that, i) preoperative $\beta$-blocking drugs did not prevent intraoperative cardiac arrhythmias and ii) preoperative $\alpha$-blockade was not judged necessary because available vasoactive drugs allowed intraoperative hemodynamic changes to be controlled whenever necessary. Intraoperative attention to patients' hemodynamics is likely to be more important than a specific hypotensive medication.

\section{Cause of hemodynamic instability in pheochromocytoma surgery?}

The above findings are to be expected. In patients undergoing pheochromocytoma removal, intraoperative increase in arterial pressure has been shown to be associated with plasma norepinephrine and epinephrine release, which occurs in all patients i) when moving the patient on the table; ii) during induction of general anesthesia and tracheal intubation in relationship with intraabdominal pressure changes associated with cough, light sedation, and insufficient relaxation; iii) when abdominal pressure changes due to the initiation of mechanical ventilation; iv) during the creation of pneumoperitoneum; and v) when the tumor is directly manipulated $(13,26,48-50)$. Increased arterial pressure is also likely to be an exaggerated response to noxious stimuli not associated with catecholamine release such as skin incision $(16,50)$. These intraoperative hypertensive responses are currently and empirically limited by increasing anesthetic depth and muscle relaxation, along with careful surgical handling of tumor tissue (10-12, $16,48-50)$. Whether anesthesia guided by bispectral index (BIS) monitoring could optimize anesthetic delivery and have a significant impact on intraoperative arterial pressure changes in patients undergoing pheochromocytoma removal remains to be investigated (51).

\section{Anesthetic technique}

Epidural and spinal anesthesias have been used alone or as a complement to general anesthesia for pheochromocytoma removal with satisfactory results $(15,22$, 29). However, they do not provide the best comfort when carrying out an adrenalectomy (10-12), and sympathetic blockade associated with spinal anesthesia does not protect against the hemodynamic effects of catecholamine release during tumor manipulation $(13,16$, $29,35)$. General anesthesia is favored in most reports $(5,11-17,24,25,27-35,41,46,47)$. Induction with thiopental, propofol, and etomidate is common practice $(16,17,32)$. Ketamine that increases catecholamine release should be logically avoided (15). Recent halogenated agents, including sevoflurane, desflurane, isoflurane, and nitrous oxide, have been recognized as being safe in patients undergoing pheochromocytoma removal $(13,15,17,24,25,29,30,34,35)$. The choice among available muscle relaxants is of secondary importance (15). Succinylcholine has been used successfully either as a bolus or as a continuous infusion $(13,15)$. Atracurium and vecuronium are routinely used by many teams $(15,16)$. Tubocurarine, gallamine, and pancuronium, which have been suggested to cause catecholamine release and to have anticholinergic and histamine releasing effects, are no longer used (52). Direct and continuous monitoring of arterial pressure via an intraarterial catheter is 
universally recommended $(5,16-18,22,23,25-34$, $41,46,47,50)$. A central venous catheter is a routine part of patient care in many reports $(18,30,49,50)$. Some teams believe that administering a vasopressor on a peripheral venous line to control transient intraor post-operative hypotension is not harmful (31). A pulmonary artery catheter was previously judged to be warranted to investigate hypotension following tumor removal (50). Actually, no monitoring has proved its usefulness for both interpretation and treatment of arterial hypotension following pheochromocytoma resection. Globally, many diagnostic tools have been reported to be highly predictive of fluid responsiveness in intensive care patients and during anesthesia (53-55). Invasive arterial pressure monitoring is routinely used during pheochromocytoma removal, allowing measurement of $\Delta$-down derived from the analysis of arterial pulse pressure waveform, as mentioned earlier (38). However, fluid loading reduced non-specifically $\Delta$-down at all times of pheochromocytoma resection similarly as in anesthetized normal patients (38). Further investigations are necessary to assess if $\Delta$-down monitoring could efficiently guide fluid resuscitation and reduce the risk of arterial hypotension following tumor removal (38). To our knowledge, other diagnostic tools such as i) stroke volume variation derived from pulse contour analysis and ii) variation of the amplitude of the pulse oximeter plethysmographic waveform together with iii) aortic flow velocity and stroke volume assessed by Doppler echocardiography or transesophageal echocardiography have not been evaluated in patients undergoing pheochromocytoma resection (53-55).

\section{Intraoperative hypotensive drugs}

Many fast-acting intravenous drug regimens have been reported to efficiently control intra- and post-operative changes in blood pressure. Their selection mainly results from local practices.

- Increasing depth of anesthesia and muscle relaxation is a common anesthetic practice to reduce intraoperative increases in blood pressure $(16,28,32,50)$. As mentioned earlier, BIS-guided anesthesia has not been studied in pheochromocytoma surgery (51).

- Phentolamine is a competitive $\alpha 1$ - and weak $\alpha 2$ adrenergic receptor antagonist that has a short duration of action (40). At the present time, continuous infusion of phentolamine is seldom administered in patients with pheochromocytoma to lower perioperative hypertensive episodes during surgical adrenalectomy (13).

- Sodium nitroprusside decreases preload and afterload (56). Its onset is immediate and recovery occurs within 1-2 min (56). It is often used as a first choice agent to treat intraoperative arterial pressure increases in patients undergoing pheochromocytoma removal $(6,16,30)$. In patients with coronary artery disease, a significant 'steal' in coronary blood flow has been documented (56). Toxic metabolites such as cyanide and thiocyanate are a concern only when the agent is administered in high doses and/or for more than $48-72 \mathrm{~h}$, in patients with abnormal renal and hepatic function, and when the infusion rate is $>$ $2 \mu \mathrm{g} / \mathrm{kg}$ per min (56).

- Nitroglycerin is a rapid-acting venodilator (57). Its onset and duration of action are rapid. It reduces preload and increases coronary blood flow by dilating collateral vessels and suppressing coronary vasospasm (57). High doses of nitroglycerin produce arteriolar vasodilation (57). Nitroglycerin is a suitable drug in patients with ischemic heart disease (57). Nitroglycerine was successfully used to decrease blood pressure in patients undergoing pheochromocytoma removal (58).

- Second-generation calcium channel antagonists, especially dihydro-pyridines (nicardipine), have powerful arterial vasodilating properties (42). This results in a reduction in afterload and an improvement in left ventricular function along with the preservation of venous return (42). Potent cerebral, renal, and coronary vasodilatory activities have been reported (42). Intravenous nicardipine decreases blood pressure in a dose-dependent fashion with a response in 1-3 min (42). The half-life is $3-7 \mathrm{~min}$. Gradual accumulation of nicardipine during infusions may prolong its duration of action. i.v. nicardipine infusion or bolus is currently used in patients undergoing pheochromocytoma removal $(18,50)$.

- Urapidil is an $\alpha$-blocking agent that was judged useful in managing hypertension following the induction of anesthesia and during tumor dissection in patients undergoing pheochromocytoma removal (22). Heart rate did not change significantly (22).

- Magnesium sulfate did not consistently produce satisfactory control of arterial pressure during handling of the tumor (23).

- Intravenous lidocaine has been consistently effective in controlling intraoperative arrhythmias in many old studies (16).

- Esmolol is an ultra short-acting cardio selective $\beta$-adrenergic blocking agent, preferred over propranolol for the control of intraoperative tachycardias or tachyarrhythmias $(18,31,59)$. The onset of action is $60 \mathrm{~s}$ with a duration of action of 10-20 min (59). The metabolism of esmolol is via the hydrolysis of ester linkages by red blood cell esterases and is not dependent on renal or hepatic function (59).

\section{Hypotension following adrenalectomy}

As can be seen from the above, various quantities and types of fluids associated with various vasopressive 
drugs, mainly norepinephrine and seldom epinephrine, have been recommended to control hypotension following tumor withdrawal, resulting in a mortality close to zero in all recent studies $(5,17,18,22-34,41$, $46,47,50)$.

\section{Postoperative care}

Hypotension following pheochromocytoma removal is definitively controlled within a few hours following surgery in most patients $(5,16,19,22,28,30,31)$. Anecdotal reports of patients requiring a $48 \mathrm{~h}$ vasopressive support are available $(1,5)$. High blood pressure requiring specific care has been reported to persist for a variable duration in $40 \%$ of patients $(5,16$, $19,22,28,30,31)$. Blood glucose concentration should be monitored for at least $24 \mathrm{~h}(6,7)$. Excessive rebound secretion of insulin may occur after removal of the tumor accounting for rare transient hypoglycemia reported up to 6 days postoperatively, which must not be missed in a patient drowsy as a result of general anesthesia $(6,7)$.

\section{Pregnancy}

Pregnancy warrants a different approach. Aggressive medical control of blood pressure with antihypertensive drugs is regarded as a major factor in accounting for the dramatic improvement in maternal and fetal outcome in patients with pheochromocytoma diagnosed during pregnancy $(48,49)$. Hypotensive drugs listed above have been used with good results $(48,49)$. Selective $\beta 1$-blockers such as metoprolol or atenolol must be favored over non-selective $\beta$-blockers such as propranolol, which were associated with growth retardations, neonatal bradycardias, and hypoglycemias in the fetus $(48,49)$.

\section{Is there a subgroup of patients who must receive hypotensive drugs, preoperatively?}

Pheochromocytoma in pregnancy requires aggressive control of blood pressure $(49,50)$. For all other patients, few non-concordant data are available concerning factors likely to be associated with intra- and postoperative hemodynamic instability in patients undergoing adrenalectomy for pheochromocytoma. In Bruynzeel et al. (47) study of 73 patients undergoing adrenalectomy for pheochromocytoma between 1995 and 2007, a high plasma norepinephrine concentration, larger tumor size, postural arterial pressure decrease after $\alpha$-blockade, and a preoperative mean arterial pressure above $100 \mathrm{mmHg}$ are predictive of intraoperative hemodynamic instability assessed by episodes of intraoperative mean arterial pressure decreases below $60 \mathrm{mmHg}$ and systolic blood pressure increases above $160 \mathrm{mmHg}$ (47). In contrast, Weismann et al. (60) investigated 49 patients and did not identify any factor predictive of intraoperative hemodynamic changes including tumor size larger than $7 \mathrm{~cm}$. Increases in arterial pressure up to $250 \mathrm{mmHg}$ have been reported in many studies of pheochromocytoma removal regardless of whether preoperative hypotensive drugs had been administered or not (16), and finally, continuous monitoring of arterial pressure and adequate intraoperative administration of fast acting drugs have allowed to achieve a mortality rate close to zero in recent studies $(5,16-19$, $22,26,27,29,31,32,34,41,47)$.

Finally, the right issue is probably to question whether there are patients with preoperative increased arterial pressure, scheduled for general or vascular surgery, for whom surgery must be postponed (61-63). In most studies on patients undergoing general and vascular surgery, preoperative arterial hypertension is associated with an increased risk of both intraoperative hypertensive crisis and myocardial ischemias requiring a drug intervention (61-63). However, preoperative arterial hypertension is associated with an increased risk of operative mortality only if arterial hypertension coexists with i) a preexisting heart disease including coronary artery disease, ii) factors likely to favor coronary artery disease such as hyperlipidemia or diabetes, and iii) symptomatic left ventricular dilatation or hypertrophy, aortic stenosis, or arterial pressure $\geq 180 / 115 \mathrm{mmHg}(61-63)$. It is recommended to administer oral or i.v. hypotensive drugs prior to surgery to such patients with hypertension-associated organ dysfunctions and/or in the case of preexisting stroke, symptoms such as headache or tinnitus, and if systolic blood pressure is $\geq 180 \mathrm{mmHg}$, and diastolic blood pressure is $\geq 115 \mathrm{mmHg}$ (61-63). For most patients, available data do not support postponing surgery on the sole argument that preoperative blood pressure is not normalized, provided that a coexisting heart disease is not diagnosed or increased blood pressure is functionally tolerated (61-63).

\section{Conclusion}

Increased knowledge of the disease, along with continuous arterial pressure monitoring, fast-acting vasoactive agents, and improvement of surgical approach have dramatically improved the outcome of patients undergoing adrenalectomy for pheochromocytoma. Preoperative hypotensive treatment of patients with life-threatening complications of high blood pressure such as congestive heart failure, stroke, coronary artery disease, dysrhythmia, blood pressure above 180/115 mmHg, and of patients with pheochromocytoma diagnosed during pregnancy is warranted. 
Systematic preoperative administration of fluids and hypotensive drugs is not supported by any evidencebased study. Intraoperative hypertensive responses are mainly due to tumor manipulation. Careful surgical handling of tumor tissue, limited intraabdominal pressure, adequate depth of anesthesia and muscular relaxation, and the use of fast-acting vasoactive agents are the only proven means for limiting intraoperative hypertension and their consequences. Administering fluid and/or vasopressor agents intraoperatively, whenever necessary, is as efficient as preoperative fluid infusion to control hypotension following tumor withdrawal. In most cases, available data do not allow the anesthetic team to postpone or refuse surgery to patients with preoperative, uncontrolled hypertension.

\section{Further studies are needed}

Prospective, placebo-controlled studies are required to confirm our conclusions. Several intricate endpoints will have to be assessed, mainly i) is preoperative drug or fluid administration associated with a perioperative decrease in morbidity or mortality; ii) are pheochromocytoma patients hypovolemic; iii) effect of vasodilating drugs, fluid infusion, and adrenalectomy on preoperative volemia and preoperative hemodynamic changes; iv) are there hemodynamic parameters and monitoring tools likely to guide pre-, intra- and post-operative resuscitation; v) is anesthesia guided by BIS monitoring likely to limit intraoperative hemodynamic changes; vi) to provide a reliable definition of perioperative hemodynamic instability; and vii) to identify a subgroup of patients likely to benefit from preoperative drug and fluid administration.

Potential investigators must be aware of the difficulty to conduct such studies. The endpoint 'intraoperative hemodynamic instability' has no consensual definition. Such studies will have to include a huge patient sample since available data indicate a mortality rate close to zero and a very low morbidity in recent studies. Studies will have to include a stratification for the three catecholamines released and the quantity of catecholamines sometimes released in various associations, and whether catecholamine release is sustained or paroxysmal. Several classes of hypotensive drugs will have to be considered. Whether such studies will be conducted is questionable due to the rarity of the disease. Ideally, until further studies are available, historical assessments that entertain the present scientific uncertainties should no longer be considered for publication.

\section{Declaration of interest}

The authors declare that there is no conflict of interest that could be perceived as prejudicing the impartiality of the review reported.

\section{Funding}

This review did not receive any specific grant from any funding agency in the public, commercial or not-for-profit sector.

\section{Acknowledgements}

We would like to thank Prof. Frederic Mercier for helpful discussion.

\section{References}

1 Guerrero MA, Schreinemakers JM, Vriens MR, Suh I, Hwang J, Shen WT, Gosnell J, Clark OH \& Duh QY. Clinical spectrum of pheochromocytoma. Journal of the American College of Surgeons 2009209 727-732. (doi:10.1016/j.jamcollsurg.2009.09.022)

2 Lenders JW, Pacak K, Walther MM, Linehan WM, Mannelli M, Friberg P, Keiser HR, Goldstein DS \& Eisenhofer G. Biochemical diagnosis of pheochromocytoma: which test is best? Journal of the American Medical Association 200220 1427-1434. (doi:10.1001/ jama.287.11.1427)

3 Kopetschke R, Slisko M, Kilisli A, Tuschy U, Wallaschofski H, Fassnacht M, Ventz M, Beuschlein F, Reincke M, Reisch N \& Quinkler M. Frequent incidental discovery of phaeochromocytoma: data from a German cohort of 201 phaeochromocytoma. European Journal of Endocrinology 2009161 355-361. (doi:10. 1530/EJE-09-0384)

4 Opocher G \& Schiavi F. Genetics of pheochromocytomas and paragangliomas. Best Practice and Research. Clinical Endocrinology and Metabolism 201024 943-956. (doi:10.1016/j.beem.2010. 05.001)

5 Pacak K, Eisenhofer G, Ahlman H, Bornstein SR, GimenezRoqueplo AP, Grossman AB, Kimura N, Mannelli M, McNicol AM \& Tischler AS. International symposium on pheochromocytoma. Pheochromocytoma: recommendations for clinical practice from the First International Symposium. October 2005. Nature Clinical Practice. Endocrinology \& Metabolism 20073 92-102. (doi:10. 1038/ncpendmet0396)

6 Jude EB \& Sridhar CB. Prolonged hypoglycaemia following surgical removal of phaeochromocytoma. Postgraduate Medical Journal 200076 39-40. (doi:10.1136/pmj.76.891.39)

7 Levin H \& Heifetz M. Phaeochromocytoma and severe protracted postoperative hypoglycaemia. Canadian Journal of Anaesthesia 1990 37 477-478. (doi:10.1007/BF03005631)

8 Proye C, Fossati P, Fontaine P, Lefebvre J, Decoulx M, Wemeau JL, Dewailly D, Rwamasirabo E \& Cecat P. Dopamine-secreting pheochromocytoma: an unrecognized entity? Classification of pheochromocytomas according to their type of secretion. Surgery $19861001154-1162$.

9 Brukamp K, Goral S, Townsend RR, Silvestry FE \& Torigian DA. Rapidly reversible cardiogenic shock as a pheochromocytoma presentation. American Journal of Medicine 2007120 1-2. (doi:10. 1016/j.amjmed.2006.08.031)

10 Pace DE, Chiasson PM, Schlachta CM, Mamazza J, Cadeddu MO \& Poulin EC. Minimally invasive adrenalectomy for pheochromocytoma during pregnancy. Surgical Laparoscopy, Endoscopy $\mathcal{E}$ Percutaneous Techniques 20022 122-125. (doi:10.1097/00129 689-200204000-00011)

11 Toniato A, Boschin IM, Opocher G, Guolo A, Pelizzo M \& Mantero F. Is the laparoscopic adrenalectomy for pheochromocytoma the best treatment? Surgery 2007141 723-727. (doi:10. 1016/j.surg.2006.10.012)

12 Kercher KW, Novitsky YW, Park A, Matthews BD, Litwin DE \& Heniford BT. Laparoscopic curative resection of pheochromocytomas. Annals of Surgery 2005241 919-926. (doi:10.1097/01.sla. $0000164175.26785 .06)$

13 Ross EJ, Prichard BNC, Kaufman L, Robertson AIG \& Harries BJ. Preoperative and operative management of patients with pheochromocytoma. BMJ 19671 191-198. (doi:10.1136/bmj.1.5534.191) 
14 Thompson JE \& Arrowod JG. Pheochromocytoma: surgical and anesthetic management. Anesthesiology 195415 658-665. (doi:10.1097/00000542-195411000-00009)

15 Brunjes S, Johns VJ \& Crane MG. Pheochromocytoma. Postoperative shock and blood volume. British Journal of Anaesthesia 1960262 393-396.

16 Desmonts JM \& Marty J. Anaesthetic management of patients with phaeochromocytoma. British Journal of Anaesthesia 198456 781-789. (doi:10.1093/bja/56.7.781)

17 Weingarten TN, Cata JP, O'Hara JF, Prybilla DJ, Pike TL, Thompson GB, Grant CS, Warner DO, Bravo E \& Sprung J. Comparison of two preoperative medical management strategies for laparoscopic resection of pheochromocytoma. Urology 2010 76 508-511. (doi:10.1016/j.urology.2010.03.032)

18 Lebuffe G, Dosseh ED, Tek G, Tytgat H, Moreno S, Tavernier B, Vallet B \& Proye CA. The effect of calcium channel blockers on outcome following the surgical treatment of pheochromocytomas and paragangliomas. Anaesthesia 200560 439-444. (doi:10. $1111 / \mathrm{j} .1365-2044.2005 .04156 . x)$

19 Chapman N, Chen CY, Fujita T, Hobbs FD, Kim SJ, Staessen JA, Tanomsup S, Wang JG, Cubeddu LX, Zarate NA, Rosales CB \& Zschaeck DW. Prazosin and propranolol in preoperative management of pheochromocytoma. Clinical Pharmacology and Therapeutics 198232 156-160. (doi:10.1038/clpt.1982.141)

20 Goldfein A. Pheochromocytome: diagnosis and anesthetic and surgical management. Anesthesiology 196324 462-471. (doi:10. 1097/00000542-196307000-00008)

21 Goldstein RE, O'Neill JA Jr, Holcomb GW III, Morgan WM III, Neblett WW III, Oates JA, Brown N, Nadeau J, Smith B, Page DL, Abumrad NN \& Scott HW Jr. Clinical experience over 48 years with pheochromocytoma. Annals of Surgery 1999229 755-764. (doi:10.1097/00000658-199906000-00001)

22 Gosse P, Tauzin-Fin P, Sesay M-B, Sautereau A \& Ballanger P. Preparation for surgery of phaeochromocytoma by blockade of $\alpha$-adrenergic receptors with urapidil: what dose? Journal of Human Hypertension 200923 1-5. (doi:10.1038/jhh.2008.172)

23 James MF. Use of magnesium sulphate in the anaesthetic management of phaeochromocytoma: a review of 17 anaesthetics. British Journal of Anaesthesia 198962 616-623. (doi:10. $1093 / \mathrm{bja} / 62.6 .616)$

24 Perry LB \& Gould AB Jr. The anesthetic management of pheochromocytoma effect of preoperative adrenergic blocking drugs. Anesthesia and Analgesia 197251 36-40. (doi:10.1213/ 00000539-197201000-00010)

25 Plouin PF, Duclos JM, Soppelsa F, Boublil G \& Chatellier G. Factors associated with perioperative morbidity and mortality in patients with pheochromocytoma: analysis of 165 operations at a single center. Journal of Clinical Endocrinology and Metabolism 200186 1480-1486. (doi:10.1210/jc.86.4.1480)

26 Poopalalingam R \& Chin EY. Rapid preparation of a patient with pheochromocytoma with labetalol and magnesium sulfate. Canadian Journal of Anaesthesia 200148 876-880. (doi:10. 1007/BF03017353)

27 Prys-Roberts C \& Farndon JR. Efficacy and safety of doxazosin for perioperative management of patients with pheochromocytoma. World Journal of Surgery 200226 1037-1042. (doi:10.1007/ s00268-002-6667-z)

28 Roizen MF, Hunt TK, Beaupre PN, Kremer P, Firmin R, Chang CN, Alpert RA, Thomas CJ, Tyrrell JB \& Cahalan MK. The effect of alpha-adrenergic blockade on cardiac performance and tissue oxygen delivery during excision of pheochromocytoma. Surgery 198394 941-945.

29 Steinsapir J, Carr AA, Prisant LM \& Bransome ED Jr. Metyrosine and pheochromocytoma. Archives of Internal Medicine 1997157 901-906. (doi:10.1001/archinte.157.8.901)

30 Ulchaker JC, Goldfarb DA, Bravo EL \& Novick AC. Successful outcomes in pheochromocytoma surgery in the modern era. Journal of Urology 1999161 764-767. (doi:10.1016/S00225347(01)61762-2)

31 Lentschener C, Gaujoux S, Thillois JM, Duboc D, Bertherat J, Ozier Y \& Dousset B. Increased arterial pressure is not predictive of haemodynamic instability in patients undergoing adrenalectomy for phaeochromocytoma. Acta Anaesthesiologica Scandinavica 2009 53 522-527. (doi:10.1111/j.1399-6576.2008.01894.x)

32 Kinney MA, Narr BJ \& Warner MA. Perioperative management of pheochromocytoma. Journal of Cardiothoracic and Vascular Anesthesia 200216 359-369. (doi:10.1053/jcan.2002.124150)

33 Newell KA, Prinz RA, Brooks MH, Glisson SN, Barbato AL \& Freark RJ. Plasma catecholamine changes during excision of pheochromocytoma. Surgery $1988 \mathbf{1 0 4} 1064-1073$.

34 Boutros AR, Bravo EL, Zanettin G \& Straffon RA. Perioperative management of 63 patients with pheochromocytoma. Cleveland Clinic Journal of Medicine 199057 613-617.

35 Sjoerdsma A, Engelman K, Waldmann TA, Cooperman LH \& Hammond WG. Pheochromocytoma: current concepts of diagnosis and treatment: Combined Clinical Staff Conference at the National Institutes of Health. Annals of Internal Medicine $1966 \mathbf{6 5}$ 1302-1326.

36 Finnerty FA Jr, Buchholz JH \& Guillaudeu RL. The blood volumes and plasma protein during levarterenol-induced hypertension. Journal of Clinical Investigation 195837 425-429. (doi:10.1172/ JCI103622)

37 Yanagawa Y, Sakamoto T \& Okada Y. Hypovolemic shock evaluated by sonographic measurement of the inferior vena cava during resuscitation in trauma patients. Journal of Trauma 200763 1245-1248. (doi:10.1097/TA.0b013e318068d72b)

38 Mallat J, Pironkov A, Destandau MS \& Tavernier B. Systolic pressure variation (Deltadown) can guide fluid therapy during pheochromocytoma surgery. Canadian Journal of Anaesthesia 2003 50 998-1003. (doi:10.1007/BF03018362)

39 Mercier FJ, Riley ET, Frederickson WL, Roger-Christoph S, Benhamou D \& Cohen SE. Phenylephrine added to prophylactic ephedrine infusion during spinal anesthesia for elective cesarean section. Anesthesiology 200195 668-674. (doi:10.1097/ 00000542-200109000-00020)

40 McMillian WD, Trombley BJ, Charash WE \& Christian RC. Phentolamine continuous infusion in a patient with pheochromocytoma. American Journal of Health-System Pharmacy 201168 130-134. (doi:10.2146/ajhp090619)

41 Witteles RM, Kaplan EL \& Roizen MF. Safe and cost-effective preoperative preparation of patients with pheochromocytoma. Anesthesia and Analgesia 200091 302-304. (doi:10.1097/ 00000539-200008000-00011)

42 Halpern NA, Goldberg M, Neely C, Sladen RN, Goldberg JS, Floyd J, Gabrielson G \& Greenstein RJ. Postoperative hypertension: a multicenter, prospective, randomized comparison between intravenous nicardipine and sodium nitroprusside. Critical Care Medicine 199220 1637-1643. (doi:10.1097/00003246-19921 2000-00006)

43 Sibal L, Jovanovic A, Agarwal SC, Peaston RT, James RA, Lennard TW, Bliss R, Batchelor A \& Perros P. Phaeochromocytomas presenting as acute crises after beta blockade therapy. Clinical Endocrinology 200665 186-190. (doi:10.1111/j.1365-2265. 2006.02571.x)

44 Papadopoulos DP, Mourouzis I, Thomopoulos C, Makris T \& Papademetriou V. Hypertension crisis. Blood Pressure 201019 328-336. (doi:10.3109/08037051.2010.488052)

45 Engelman K, Jéquier E, Udenfriend S \& Sjoerdsma A. Metabolism of alpha-methyltyrosine in man: relationship to its potency as an inhibitor of catecholamine biosynthesis. Journal of Clinical Investigation 196847 568-576. (doi:10.1172/JCI105753)

46 Tcherdakoff P, Menard J, Bedrossian J, Vaysse J, Alexandre JM, Desmonts JM \& Milliez P. Alpha-methyl -para-tyrosine in the prolonged treatment of malignant pheochromocytoma and preoperative care of benign pheochromocytoma: preliminary study. Journal of Urology and Nephrology $1972 \mathbf{7 8} 744-747$.

47 Bruynzeel H, Feelders RA, Groenland TH, van den Meiracker AH, van Eijck CH, Lange JF, de Herder WW \& Kazemier G. Risk factors for hemodynamic instability during surgery for pheochromocytoma. Journal of Clinical Endocrinology and Metabolism 201095 678-685. (doi:10.1210/jc.2009-1051) 
48 Oliva R, Angelos P, Kaplan E \& Bakris G. Pheochromocytoma in pregnancy: a case series and review. Hypertension $2010 \mathbf{5 5}$ 600-606. (doi:10.1161/HYPERTENSIONAHA.109.147579)

49 Sarathi V, Lila A, Bandgar T, Menon P \& Shah N. Pheochromocytoma and pregnancy: a rare but dangerous combination. Endocrine Practice 200926 1-21.

50 Joris JL, Hamoir EE, Hartstein GM, Meurisse MR, Hubert BM, Charlier CJ \& Lamy ML. Hemodynamic changes and catecholamine release during laparoscopic adrenalectomy for pheochromocytoma. Anesthesia and Analgesia 199988 16-21. (doi:10. 1097/00000539-199901000-00004)

51 Myles PS, Leslie K, McNeil J, Forbes A \& Chan MT. Bispectral index monitoring to prevent awareness during anaesthesia: the B-Aware randomised controlled trial. Lancet 2004363 1757-1763. (doi:10.1016/S0140-6736(04)16300-9)

52 Lavery GG, Clarke RS \& Watkins J. Histaminoid responses to atracurium, vecuronium and tubocurarine. Annales Françaises d'Anesthésie-Réanimation 19854 180-183. (doi:10.1016/S07507658(85)80196-9)

53 Marik PE, Cavallazzi R, Vasu T \& Hirani A. Dynamic changes in arterial waveform derived variables and fluid responsiveness in mechanically ventilated patients. A systematic review of the literature. Critical Care Medicine 200937 2642-2647. (doi:10. 1097/CCM.Ob013e3181a590da)

54 Monnet X, Rienzo M, Osman D, Anguel N, Richard C, Pinsky MR \& Teboul JL. Esophageal Doppler monitoring predicts fluid responsiveness in critically ill ventilated patients. Intensive Care Medicine 200531 1195-1201. (doi:10.1007/s00134-0052731-0)

55 Axler O, Megarbane B, Lentschener C \& Fernandez H. Comparison of cardiac output measured with echocardiographic volumes and aortic Doppler methods during mechanical ventilation. Intensive Care Medicine 200329 208-217. (doi:10.1007/s00134-0021582-1)

56 Friederich JA \& Butterworth JF IV. Sodium nitroprusside: twenty years and counting. Anesthesia and Analgesia 1995 81 152-162. (doi:10.1097/00000539-199507000-00031)
57 AbdelDayem TM, El-Mawardy R, Abdel-Dayem MK, Rayan M, El-Mahmoudy A, Shawky G \& Nammas W. Assessment of coronary flow parameters by transesophageal echocardiography in patients with isolated coronary artery ectasia: effect of intravenous nitroglycerin. Echocardiography $2010 \quad \mathbf{2 7}$ 1004-1010. (doi:10.1111/j.1540-8175.2010.01164.x)

58 Hamilton A, Sirrs S, Schmidt N \& Onrot J. Anaesthesia for phaeochromocytoma in pregnancy. Canadian Journal of Anaesthesia 199744 654-657. (doi:10.1007/BF03015450)

59 Gray RJ. Managing critically ill patients with esmolol: an ultra short-acting $\beta$-adrenergic blocker. Chest 198893 398-403. (doi:10.1378/chest.93.2.398)

60 Weismann D, Fassnacht M, Weinberger F, Hamelmann W, Diehl S, Lorenz K, Baerlehner E, Reincke M, Beuschlein F, Knoefel W, Nies C, Hahner S \& Allolio B. Intraoperative haemodynamic stability in patients with phaeochromocytoma - minimally invasive vs conventional open surgery. Clinical Endocrinology $2006 \mathbf{6 5} 352-358$. (doi:10.1111/j.1365-2265. 2006.02603.x)

61 Lee TH, Marcantonio ER, Mangione CM, Thomas EJ, Polanczyk CA, Cook EF, Sugarbaker DJ, Donaldson MC, Poss R, Ho KK, Ludwig LE, Pedan A \& Goldman L. Derivation and prospective validation of a simple index for prediction of cardiac risk of major noncardiac surgery. Circulation $1999 \quad 100$ 1043-1049. (doi:10.1161/01.CIR.100.10.1043)

62 Roizen MF. Anesthetic implications of concurrent diseases. In Anesthesia, edn 5, pp 903-1015. Ed. RD Miller, Philadelphia: Churchill Livingstone, 2000.

63 Howell SJ, Sear YM, Yeates D, Goldacre M, Sear JW \& Foëx P. Risk factors for cardiovascular death after elective surgery under general anaesthesia. British Journal of Anaesthesia 1998 80 14-19. (doi:10.1093/bja/80.1.14)

Received 31 May 2011

Accepted 6 June 2011 